\title{
Predictors and mediators of differences in soft drinks consumption according to gender and plans of further education among Norwegian secondary-school children
}

\author{
Marit Hilsen ${ }^{1,2,3, *}$, Saskia J te Velde ${ }^{3}$, Elling Bere ${ }^{1}$ and Johannes Brug ${ }^{3}$ \\ 'Department of Public Health, Sport and Nutrition, Postboks 422, University of Agder, 4604 Kristiansand, \\ Norway: ${ }^{2}$ Department of Nutrition, Faculty of Medicine, University of Oslo, Oslo, Norway: ${ }^{3}$ Department of \\ Epidemiology \& Biostatistics and the EMGO Institute for Health and Care Research, VU University Medical \\ Centre, Amsterdam, the Netherlands
}

Submitted 8 March 2011: Accepted 11 0ctober 2011: First published online 29 November 2011

\begin{abstract}
Objective: To explore mediators of gender and educational differences in sugarsweetened soft drinks consumption (SDC) and whether gender and level of future education moderate the associations of accessibility, modelling, attitudes and preferences with SDC.

Design: A cross-sectional school-based survey within the Fruits and Vegetables Makes the Marks (FVMM) project from 2005.

Setting: The questionnaires were completed by the pupils in the classroom guided by a trained project worker during one class session. The questionnaire included questions on SDC (times/week), the potential mediators and moderators. Multilevel linear regression models were used to calculate the mediating and moderating effects.

Subjects: A total of 2870 children in 9 th and 10 th grade (mean age 15.5 years) at thirty-three Norwegian secondary schools were included in the present study.

Results: Girls $(B=-1 \cdot 06)$ and pupils planning higher education $(B=-0 \cdot 69)$ reported lower frequency of SDC. The strongest mediators were accessibility and modelling for future educational plans differences (explaining alone respectively $69 \%$ and 44\%) and attitudes and preferences for gender differences (explaining alone respectively $57 \%$ and $51 \%$ ). Significant but small moderating effects were found, and all associations between the mediators and SDC were in the same direction for both genders and for those with and without plans of higher future education.

Conclusions: Preferences and modelling may contribute to gender and educational differences in SDC. The small moderating effects indicate that interventions aiming to reduce SDC can target the same mediators for boys and girls and children planning different levels of future education.
\end{abstract}

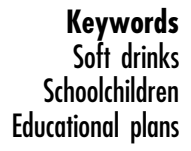

Keywords

Sott drinks Educational plans
Sugar-sweetened carbonated soft drinks consumption (SDC) has been associated with increased energy intake and body weight, lower intake of several nutrients and an increased risk of type 2 diabetes $^{(1)}$, dental caries and potential enamel erosion ${ }^{(2)}$.

The WHO recommends a maximum of $10 \%$ of energy intake from free sugars ${ }^{(3)}$. A study among 8th graders in Norway showed that $18 \%$ of energy intake came from free sugars; for $89 \%$ of the children more than $10 \%$ of energy intake was from free sugars, and soft drinks contributed $30 \%$ to total added sugar intakes ${ }^{(4)}$. Studies in other countries also show high sugar intakes among youth and have reported an increase in SDC among children and adolescents $^{(5)}$ as well as an increase in availability of soft drinks $^{(6)}$ in recent years.
Earlier studies further show that boys drink more soft drinks than girls ${ }^{(7,8)}$, that consumption of soft drinks increases with age ${ }^{(5,8,9)}$ and that youth from lower socio-economic groups drink more soft drinks ${ }^{(7,10,11)}$. It has also been reported among younger adults that, compared with low consumers of sugar-sweetened soft drinks, the high consumption group has a lower proportion of physically active individuals and a higher proportion of regular smokers ${ }^{(12)}$. The Fruits and Vegetables Make the Marks (FVMM) project indicated that gender, educational plans, dieting, accessibility at home, parental and peer modelling, attitudes and preferences all were strong correlates of adolescents' $\mathrm{SDC}^{(7)}$. Preferences $^{(8)}$, attitudes ${ }^{(13-16)}$ and modelling ${ }^{(8,17,18)}$ have been found to be associated with SDC among adolescents in other studies as well. Furthermore, children attending 


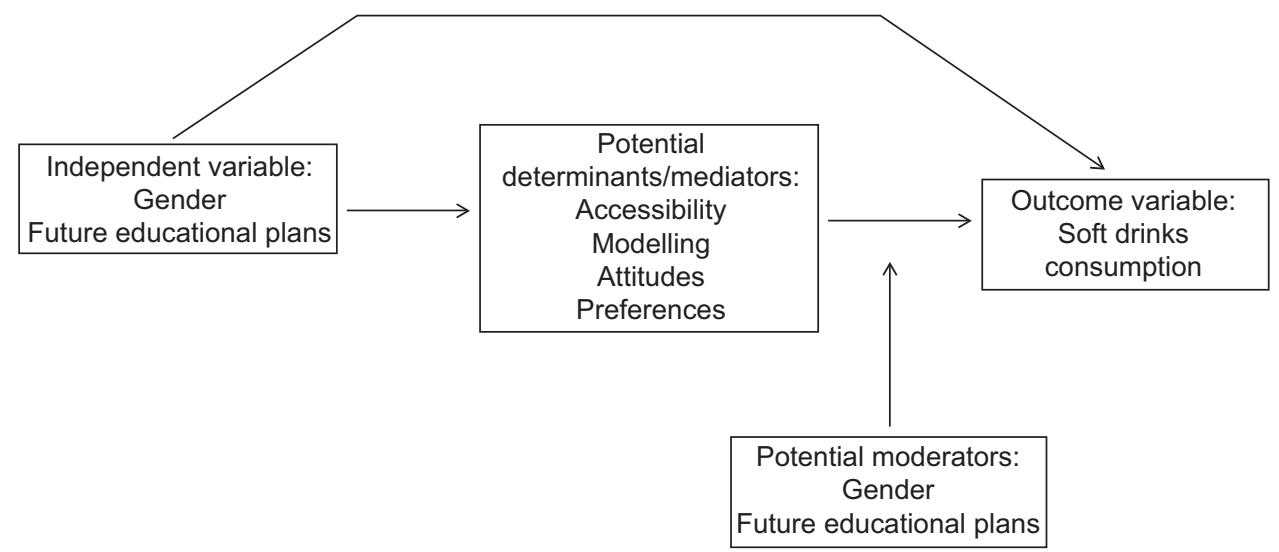

Fig. 1 Model of the potential determinants, mediators and moderators of soft drinks consumption

lower levels of education are more likely to drink soft drinks than higher education students ${ }^{(7)}$.

In order to reduce SDC among children and adolescents more insight is needed into what may explain the gender and educational differences in SDC. Based on health behaviour theory and the previous findings of other studies outlined above we know that the adolescents' perceived home accessibility, example behaviour by parents and friends (modelling), attitudes and preferences of soft drinks are associated with SDC. Additionally, given the fact that such potential determinants have also been found to differ according to gender and level of education, we aimed to explore these determinants/correlates further regarding whether they also were associated with gender and future educational plans in the present sample, and if these mediated the intake differences according gender and education. The aims of the present study were therefore to explore whether accessibility, modelling, attitudes and preferences can explain the differences in SDC according to gender and the pupils' anticipated level of secondary education. The EnRG framework ${ }^{(19)}$ posits that sociodemographic variables can importantly moderate determinant-behaviour relationships. Gender as well as level of education has been found to be an important moderator of health behaviour change in earlier studies, and interventions are often tailored to level of education or gender. Due to the large gender and socioeconomic differences in SDC we wanted to explore whether gender and the pupils' further educational plans moderate the association between the potential mediators and SDC in the present study. The study therefore also explored whether the associations of accessibility, modelling, attitudes and preferences with SDC differ according to gender and level of anticipated further education (Fig. 1).

\section{Methods}

\section{Study sample and procedure}

The data are from the third follow-up measurement (2005 survey) of the Fruits and Vegetables Make the Marks
(FVMM) project. Pupils from 9th and 10th grade (mean age estimated to $15 \cdot 5$ years) of thirty-three lower secondary schools in Hedmark and Telemark counties participated. A total of 2870 pupils completed the school-based questionnaire with $51 \cdot 1 \%$ boys, $51 \cdot 1 \%$ th graders and $49 \cdot 1 \%$ pupils who planned to enrol in higher levels of further education after graduation from lower secondary school. The questionnaire was completed by the pupils in the classroom guided by a trained project worker in one school class session ( $45 \mathrm{~min})$.

\section{Measurements}

The questions on potential determinants/mediators in the survey questionnaire were based on focus groups interviews among 9th and 10th graders and a pre-test of the questionnaire $^{(7)}$. Frequency of SDC, home and school social and physical environmental and personal potential determinants of SDC were included in the questionnaire, as well as sociodemographic factors and gender.

\section{Main outcome variable: frequency of sugar-sweetened soft drinks consumption}

Two separate questions were included in the questionnaire to be able to distinguish between the pupils' consumption of sugar-sweetened soft drinks and artificially sweetened soft drinks. Weekly frequency of SDC among the pupils was assessed with one question: 'How often do you drink soft drinks?' The response categories for this question had ten alternatives ranging from 'never', 'less than once per week', 'once per week' ... to 'every day' and 'several times per day'. The score of this variable ranged from 0 (never), 0.5 (less than once per week), 1 (once per week) ... to 7 (every day) and 10 (several times per day). Test-retest results from a study among 6th graders ${ }^{(20)}$ showed an intraclass correlation of 0.72 between two assessments $14 \mathrm{~d}$ apart.

\section{Potential moderating variables: sociodemographic factors}

The pupils were asked to indicate their plans for further education (future education) after graduation from secondary 
school: 'university or college', 'technical or vocational education', 'no further education' and 'others'. This variable was dichotomized into higher education (university/ college; score $=1)$ or not $($ score $=0)$. The pupils reported their gender ( girl, score $=1$; boy, score $=0$ ).

\section{Potential mediators}

Perceived accessibility at home of soft drinks was assessed by three questions (Cronbach's $\alpha=0 \cdot 70^{(7)}$ ). Modelling, i.e. descriptive norms from important others, was assessed with four items (Cronbach's $\alpha=0 \cdot 68^{(7)}$ ). Attitudes was assessed by three statements (Cronbach's $\alpha=0 \cdot 65^{(7)}$ ). For these mediators, mean scores were calculated if at least two items were completed, excluding thirty-nine, eighty-six and thirty-six pupils for accessibility, modelling and attitudes, respectively. Preferences was assessed by one question. The questions/statements, ranges and scores of all the potential mediators are presented in the Appendix.

\section{Statistical analyses}

First, regression models were used to estimate the overall relationship of future education and gender with SDC (path c; Fig. 2). Second, the relationship of future education plans and gender with the potential mediators (path a) was estimated. Third, the relationship between the potential mediators and SDC (path b) was calculated in a model including the mediator and the predictor. This also provided the direct relationship of future education and gender with SDC (path $c^{\prime}$ ). Mediated effects were found by means of the product-of-coefficients method ${ }^{(21)}$. The standard error term was calculated by the equation ${ }^{(22)}$ : $\mathrm{SE}=\sqrt{b^{2} s_{a}^{2}+a^{2} s_{b}^{2}+s_{a}^{2} s_{b}^{2}}$, where $a$ and $b$ are unstandardized regression coefficients and $s_{a}$ and $s_{b}$ are their standard errors. The sE was used to construct a 95\% confidence interval for the mediated effects. Single and multiple mediator models were run and proportion mediated was calculated as $a \times b / c$ and as $\sum(a \times b) / c$.

To allow interpretation of first-order effects of the moderator (future education or gender) and predictor as average effects, the predictor (accessibility, modelling, attitudes and preferences) variables were standardized. Interaction terms were calculated between the standardized predictor variables and the potential moderator. To test whether future education and/or gender were moderators of the association of accessibility/modelling/attitudes/ preferences with SDC, a three-step approach was applied. The standardized variable ( $Z$-score) of the predictor was entered first, in the second step the moderator variable was entered, and in the third step the interaction term was included. The effect size was calculated by subtracting $R_{1}$ square from $R_{2}$ square $^{(23)}$. We used a significance level for the moderated effects of $\alpha=0 \cdot 1$.

All analyses with gender as the predictor or moderator variable were adjusted for future education and grade, and all analyses regarding future education were adjusted for gender and grade. The statistical analyses were conducted using the SPSS statistical software package version 17 (SPSS Inc., Chicago, IL, USA).

\section{Results}

\section{Sample characteristics}

Pupils with higher future education plans and girls reported a lower mean SDC frequency compared with pupils without plans of higher education and boys (Table 1). Pupils not planning to enrol in higher education and boys also had higher scores on all potential mediators.

\section{Mediation of the gender-sugar-sweetened soft drinks consumption association}

The overall association between gender and SDC confirmed that girls had lower consumption frequency than boys (regression coefficient $B=-1 \cdot 06$, 95\% CI $-1 \cdot 30$, $-0 \cdot 83$; Table 2 , path c). Table 2 also shows the associations between gender and the potential mediators (path a), the associations between the potential mediators and SDC (path b) and the mediated effects (ab). Preferences explained alone $56.9 \%$ of the variation while attitudes, accessibility and modelling explained alone $51.0 \%$, $27 \cdot 3 \%$ and $12 \cdot 5 \%$, respectively. Combined the mediators explained $63 \%$ of the gender variation in SDC. The direct effect of gender on SDC was still significant after adjusting for the mediators (Table 2, path $\mathrm{c}^{\prime}$ ).

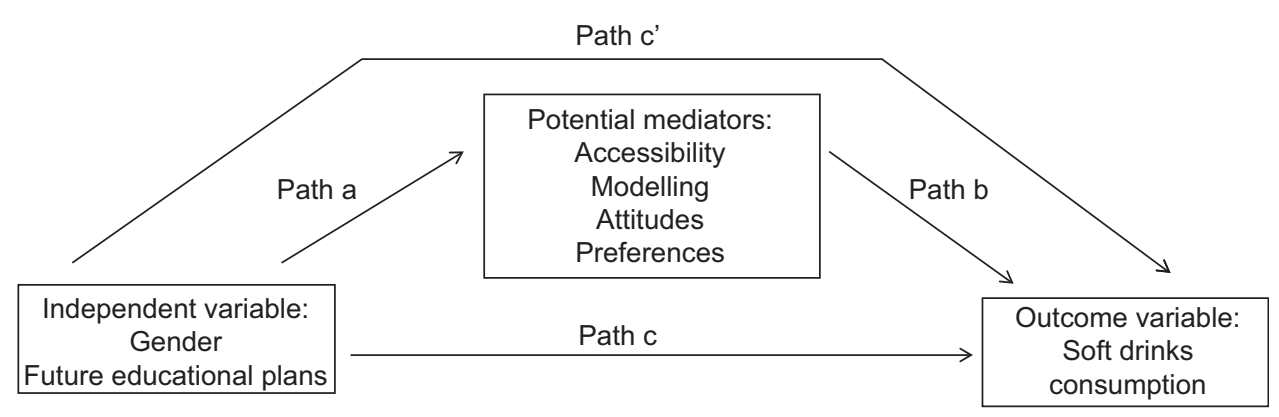

Fig. 2 Model of the mediation paths in the association between gender/future education plans and soft drinks consumption 
Table 1 Soft drinks consumption (times/week, mean and standard deviation) and the potential predictors and mediators by gender and future educational plans: Norwegian 9th and 10th graders ( $n$ 2870, mean age 15.5 years), Fruits and Vegetables Makes the Marks (FVMM) project, 2005

\begin{tabular}{|c|c|c|c|c|c|}
\hline & $\begin{array}{l}\text { Number of } \\
\text { questions }\end{array}$ & $\begin{array}{l}\text { Range per } \\
\text { question }\end{array}$ & & Mean & SD \\
\hline \multirow[t]{4}{*}{ Soft drinks consumption } & \multirow[t]{4}{*}{1} & \multirow[t]{4}{*}{$0-10$} & No plans of higher education & $3 \cdot 2$ & $2 \cdot 7$ \\
\hline & & & Plans of higher education & $2 \cdot 4$ & $2 \cdot 2$ \\
\hline & & & Boys & $3 \cdot 3$ & $2 \cdot \overline{6}$ \\
\hline & & & Girls & $2 \cdot 3$ & $2 \cdot 2$ \\
\hline \multirow[t]{4}{*}{ Accessibility } & \multirow[t]{4}{*}{3} & \multirow[t]{4}{*}{$0-10$} & No plans of higher education & $6 \cdot 8$ & $5 \cdot 1$ \\
\hline & & & Plans of higher education & $5 \cdot 6$ & $4 \cdot 6$ \\
\hline & & & Boys & $6 \cdot 8$ & 4.9 \\
\hline & & & Girls & $5 \cdot 7$ & $5 \cdot 0$ \\
\hline \multirow[t]{4}{*}{ Modelling } & \multirow[t]{4}{*}{4} & \multirow[t]{4}{*}{$0-10$} & No plans of higher education & $10 \cdot 6$ & $6 \cdot 8$ \\
\hline & & & Plans of higher education & $8 \cdot 3$ & $7 \cdot 0$ \\
\hline & & & Boys & $10 \cdot 0$ & $6 \cdot 3$ \\
\hline & & & Girls & $9 \cdot 1$ & $6 \cdot 3$ \\
\hline \multirow[t]{4}{*}{ Attitudes } & \multirow[t]{4}{*}{3} & \multirow[t]{4}{*}{$-2-2$} & No plans of higher education & $-1 \cdot 3$ & $3 \cdot 2$ \\
\hline & & & Plans of higher education & $-2 \cdot 2$ & $2 \cdot 9$ \\
\hline & & & Boys & -0.9 & $3 \cdot 2$ \\
\hline & & & Girls & $-2 \cdot 5$ & $2 \cdot 8$ \\
\hline \multirow[t]{4}{*}{ Preferences } & \multirow[t]{4}{*}{1} & \multirow[t]{4}{*}{$0-10$} & No plans of higher education & $7 \cdot 9$ & $2 \cdot 7$ \\
\hline & & & Plans of higher education & $7 \cdot 2$ & $2 \cdot 3$ \\
\hline & & & Boys & $8 \cdot 2$ & $2 \cdot 4$ \\
\hline & & & Girls & $6 \cdot 8$ & $3 \cdot 0$ \\
\hline
\end{tabular}

\section{Mediation of the future education-sugar- sweetened soft drinks consumption association}

The overall association between future education and SDC showed that pupils planning to enrol in higher education reported lower frequency of consumption ( $B=-0 \cdot 69,95 \%$ CI $-0 \cdot 93,-0 \cdot 45$; Table 3 , path c). Table 3 shows the associations between future education and the potential mediators (path a), the associations between the potential mediators and SDC (path b) and the mediated effects (ab). All mediated effects were significant, with modelling explaining alone 69.1\%, while accessibility, preferences and attitudes explained alone 43.7\%, 30.5\% and $29.6 \%$, respectively. Together, the mediators explained $80 \%$ of the variation in SDC. The direct effect of future education on SDC was not significant after adjusting for the mediators (Table 3, path $\mathrm{c}^{\prime}$ ).

\section{Gender as a moderator of the association between the potential determinants and sugar- sweetened soft drinks consumption}

Significant interactions between gender and accessibility $(P=0 \cdot 028)$, gender and modelling $(P=0 \cdot 003)$ and gender and attitudes $(P=0 \cdot 033)$ were found. Stratification by gender showed that the association between attitudes and SDC was stronger among girls $(B=1 \cdot 25,95 \%$ CI $1 \cdot 11$, $1 \cdot 39)$ than boys $(B=1 \cdot 00,95 \%$ CI $0 \cdot 83,1 \cdot 16)$. The association of accessibility with SDC was stronger for boys $(B 1 \cdot 57,95 \%$ CI $1 \cdot 41,1 \cdot 73)$ than girls $(B=1 \cdot 37,95 \%$ CI $1 \cdot 25,1 \cdot 48)$. Also the association of modelling with SDC was stronger for boys $(B=1 \cdot 55,95 \%$ CI $1 \cdot 39,1 \cdot 71)$ compared with girls $(B=1 \cdot 26,95 \%$ CI $1 \cdot 12,1 \cdot 48)$. The differences in explained variances $\left(R^{2}\right)$ of the potential mediators were small, ranging from $0 \cdot 001$ for preferences to $0 \cdot 004$ for modelling.

\section{Future education as a moderator of the association between the potential determinants and sugar-sweetened soft drinks consumption}

Significant interactions between future education and modelling $(P=0 \cdot 038)$, future education and attitudes $(P=0 \cdot 001)$ and future education and preferences $(P=0 \cdot 001)$ were found. Stratification by educational plans showed that the association between modelling and SDC was stronger among pupils with plans of future higher education ( $B=1 \cdot 56,95 \%$ CI $1 \cdot 40,1 \cdot 71$ ) than among pupils without plans of such future education ( $B=1 \cdot 30,95 \%$ CI $1 \cdot 51,1 \cdot 45)$. The association of attitudes with SDC was stronger among pupils without plans of higher education $(B=1 \cdot 29$, 95\% CI $1 \cdot 12,1 \cdot 45)$ compared with pupils with plans of higher education $(B=0 \cdot 92,95 \%$ CI $0 \cdot 78,1 \cdot 07)$. Also the association of preferences with SDC was stronger for pupils without plans of higher education $(B=1 \cdot 35,95 \%$ CI $1 \cdot 16,1 \cdot 53)$ than for pupils with plans of higher education ( $B=0 \cdot 99,95 \%$ CI $0 \cdot 86$, $1 \cdot 13)$. The effect sizes, measured by the differences in explained variances $\left(R^{2}\right)$ of the potential mediators, were small, ranging from 0 for accessibility to 0.006 for attitudes. This means that the interaction effect accounts for up to $0 \cdot 6 \%$ of the variance in SDC.

\section{Discussion}

The present study supports earlier findings regarding gender and educational differences in SDC and further suggests that these differences were strongly associated with gender differences in attitudes and preferences and educational differences in accessibility and modelling. Significant, moderating effects were found. The association between attitudes and SDC was stronger for girls, 
Table 2 Mediated effects in the association between gender and soft drinks consumption by accessibility/modelling/attitudes/preferences: Norwegian 9th and 10th graders ( $n$ 2870, mean age 15.5 years), Fruits and Vegetables Makes the Marks (FVMM) project, 2005

\begin{tabular}{|c|c|c|c|c|c|c|c|c|c|c|}
\hline & \multicolumn{2}{|c|}{ Path c } & \multicolumn{2}{|c|}{ Path c' } & \multicolumn{2}{|c|}{ Path a } & \multicolumn{2}{|c|}{ Path b } & \multirow[b]{2}{*}{$a b$} & \multirow[b]{2}{*}{$95 \% \mathrm{Cl}$} \\
\hline & $\begin{array}{l}\text { Regression } \\
\text { coefficient }\end{array}$ & $95 \% \mathrm{Cl}$ & $\begin{array}{l}\text { Regression } \\
\text { coefficient }\end{array}$ & $95 \% \mathrm{Cl}$ & $\begin{array}{l}\text { Regression } \\
\text { coefficient }\end{array}$ & $95 \% \mathrm{Cl}$ & $\begin{array}{l}\text { Regression } \\
\text { coefficient }\end{array}$ & $95 \% \mathrm{Cl}$ & & \\
\hline $\begin{array}{l}\text { Soft drinks consumption } \\
\text { (times/week) }\end{array}$ & $-1 \cdot 06$ & $-1 \cdot 30,-0 \cdot 83$ & & & & & & & & \\
\hline $\begin{array}{l}\text { Accessibility }(0 ;+7) \\
\text { Modelling }(0 ;+10) \\
\text { Attitudes }(-2 ;+2) \\
\text { Preferences }(0 ;+10) \\
\text { All mediators }\end{array}$ & & & $\begin{array}{l}-0.78 \\
-0.91 \\
-0.53 \\
-0.46 \\
-0.39\end{array}$ & $\begin{array}{l}-0.98,-0.59 \\
-1.11,-0.71 \\
-0.75,-0.31 \\
-0.68,-0.24 \\
-0.57,-0.21\end{array}$ & $\begin{array}{l}-0.33 \\
-0.15 \\
-0.51 \\
-1 \cdot 48 \\
-\end{array}$ & $\begin{array}{l}-0.50,-0.17 \\
-0.31, \quad 0.00 \\
-0.61,-0.41 \\
-1 \cdot 75,-1.22 \\
-\end{array}$ & $\begin{array}{l}0.87 \\
0 \cdot 86 \\
1.05 \\
0.41\end{array}$ & $\begin{array}{l}0.81,0.93 \\
0.79,0.92 \\
0.95,1.16 \\
0.37,0.45\end{array}$ & $\begin{array}{l}-0.29 \\
-0.13 \\
-0.54 \\
-0.61 \\
-1.57\end{array}$ & $\begin{array}{l}-0.43,-0.15 \\
-0.26, \quad 0.00 \\
-0.66,-0.42 \\
-0.73,-0.48 \\
-1 \cdot 80,-1.34\end{array}$ \\
\hline
\end{tabular}

Path c, total (overall) effect on soft drinks consumption; path c', direct effect on soft drinks consumption when adjusted for the mediator; path a, association between gender and mediator; path b, association between mediator and soft drinks consumption; ab, mediated effect using the product-of-coefficient test.

All analyses are adjusted for future education plans and grade. Gender is coded 0 for boys and 1 for girls.

Table 3 Mediated effects in the association between future education plans and soft drinks consumption by accessibility/modelling/attitudes/preferences: Norwegian 9th and 10th graders ( $n$ 2870, mean age $15 \cdot 5$ years), Fruits and Vegetables Makes the Marks (FVMM) project, 2005

\begin{tabular}{|c|c|c|c|c|c|c|c|c|c|c|}
\hline & \multicolumn{2}{|c|}{ Path c } & \multicolumn{2}{|c|}{ Path c' } & \multicolumn{2}{|c|}{ Path a } & \multicolumn{2}{|c|}{ Path b } & \multirow[b]{2}{*}{$a b$} & \multirow[b]{2}{*}{$95 \% \mathrm{Cl}$} \\
\hline & $\begin{array}{l}\text { Regression } \\
\text { coefficient }\end{array}$ & $95 \% \mathrm{Cl}$ & $\begin{array}{l}\text { Regression } \\
\text { coefficient }\end{array}$ & $95 \% \mathrm{Cl}$ & $\begin{array}{l}\text { Regression } \\
\text { coefficient }\end{array}$ & $95 \% \mathrm{Cl}$ & $\begin{array}{l}\text { Regression } \\
\text { coefficient }\end{array}$ & $95 \% \mathrm{Cl}$ & & \\
\hline $\begin{array}{l}\text { Soft drinks consumption } \\
\text { (times/week) }\end{array}$ & -0.69 & $-0.93,-0.45$ & & & & & & & & \\
\hline $\begin{array}{l}\text { Accessibility }(0 ;+7) \\
\text { Modelling }(0 ;+10) \\
\text { Attitudes }(-2 ;+2) \\
\text { Preferences }(0 ;+10) \\
\text { All mediators }\end{array}$ & & & $\begin{array}{l}-0.40 \\
-0.21 \\
-0.49 \\
-0.49 \\
-0.14\end{array}$ & $\begin{array}{l}-0.58, \quad-0.20 \\
-0.41, \quad 0.00 \\
-0.70, \quad-0.27 \\
-0.70,-0.27 \\
-0.31,-0.04\end{array}$ & $\begin{array}{l}-0.35 \\
-0.56 \\
-0.19 \\
-0.52 \\
-\end{array}$ & $\begin{array}{c}-0.51,-0.18 \\
-0.71,-0.40 \\
-0.29,-0.09 \\
-0.78,-0.25 \\
-\end{array}$ & $\begin{array}{l}0 \cdot 87 \\
0.86 \\
1 \cdot 05 \\
0 \cdot 41\end{array}$ & $\begin{array}{l}0.81,0.93 \\
0.79,0.92 \\
0.95,1.16 \\
0.37,0.45\end{array}$ & $\begin{array}{l}-0.32 \\
-0.48 \\
-0.20 \\
-0.21 \\
-1.20\end{array}$ & $\begin{array}{l}-0.44,-0.16 \\
-0.61,-0.34 \\
-0.31,-0.09 \\
-0.32,-0.10 \\
-1.42,-0.97\end{array}$ \\
\hline
\end{tabular}

Path c, total (overall) effect on soft drinks consumption; path $\mathrm{c}^{\prime}$, direct effect on soft drinks consumption when adjusted for the mediator; path a, association between future education plans and mediator; path $\mathrm{b}$, association between mediator and soft drinks consumption; ab, mediated effect using the product-of-coefficient tes

All analyses are adjusted for gender and grade. Planning higher education is coded 1 and not planning higher education is coded 0. 
while the association between accessibility (and modelling) and SDC was stronger for boys. The association between modelling and SDC was stronger for pupils with plans of higher education, while the association between preferences (and attitudes) and SDC was stronger for pupils without plans of higher education. However, although gender and future education plans statistically significantly moderated these associations the moderation effects were too minor to be practically relevant; and the associations between mediators and SDC were always in the same direction for both genders and for those with and without future education plans. A previous review reported that gender was the most convincing moderator regarding intervention studies, where in general girls responded better to interventions addressing energy balance-related behaviours than boys ${ }^{(22)}$. However, the two included studies on soft drinks consumption showed mixed results ${ }^{(24,25)}$, with only one showing a significant moderating intervention effect by gender ${ }^{(25)}$. Our hypothesis that gender and education plans would moderate the association between presumed determinants of SDC and intakes was thus not supported by the data. This is of importance for interventions and policies; the results of our study do not appear to justify targeted approaches - i.e. different messages or approaches according to gender or education plans - in interventions aiming to reduce SDC in secondary-school pupils in Norway.

Disparities in SDC in relation to gender ${ }^{(7,8,10,11,17)}$ and level of education as well as other indicators of socioeconomic position $^{(7,10,11)}$ have been well documented. However, no studies explored what could explain the relationship between gender/indicators of socio-economic position and SDC. Earlier, preferences and perceived accessibility at home had been reported to be the strongest mediator of respectively gender ${ }^{(7)}$ and parental education disparities in fruit and vegetable consumption among adolescents in Norway ${ }^{(26)}$.

In the current study, modelling by family and friends was not only associated with SCD, but also with future educational plans, and identified as a significant mediator. If indeed pupils with no plans for higher future education live in families or have close friends of lower socio-economic position, it can be expected that their family and friends engage in more unhealthy behaviours, e.g. high SDC. It is well known that family and friends' socio-economic position is related to engagement in healthy behaviours ${ }^{(6,11)}$. Future intervention programmes addressing educational disparities in SDC may therefore need to take into account the pupils' accessibility and their family and friends' behaviours. That is, such intervention programmes should especially be focused on reducing accessibility of SDC in the home and school environments: banning of soft drinks vending machines in schools, for example, and try to provide positive role models in the home and school environment.

In addition to being associated with SDC, preferences was also associated with gender, and found to be a mediator of the gender-SDC association. Preference has also been reported as the strongest mediator of the association between gender and fruit and vegetable intake $^{(27)}$. Preference is a strong driver of intake, and our finding suggests that success in interventions to reduce SDC will be harder among boys.

The present study has some limitations. The reliability of the specific SDC intake was assessed (test-retest reliability was relatively high; $r=0 \cdot 72$ ) and the relative validity has been assessed among 6th graders using similar frequency questions for a range of food and drink intakes indicating acceptable validity ${ }^{(20)}$, but the relative validity of the specific questions used in the present study was not tested. The current study is based on cross-sectional data. In order to explore further and gain more insight to whether the potential mediators really can explain the observed variance in SDC and whether gender and educational plans are significant moderators, longitudinal analyses as well as intervention studies are needed.

\section{Conclusions}

Accessibility, parental and peer modelling, attitudes and preferences were the strongest mediators of educational and gender differences in SDC in Norwegian secondaryschool students. This suggests that future interventions should address modelling and preferences in order to decrease the gender and SES disparities in SDC intake. Lack of substantial moderation indicates that interventions on reducing SDC for girls and boys, and students planning to attend higher and lower levels of education, should target the same mediators, namely accessibility, modelling, attitudes and preferences.

\section{Acknowledgements}

The project was funded by the Norwegian Research Council. The authors declare that they have no competing interests. E.B. conceived the 2005 survey of the FVMM project. M.H., S.J.t.V. and J.B. designed the present study. M.H. and S.J.t.V. analysed the data. All authors contributed to the interpretation. M.H. drafted the manuscript and S.J.t.V., J.B. and E.B. critically revised it. All authors approved of the final manuscript.

\section{References}

1. Vartanian LR, Schwartz MB \& Brownell KD (2007) Effects of soft drink consumption on nutrition and health: a systematic review and meta-analysis. Am J Public Health 97, 667-675.

2. Tahmassebi JF, Duggal MS, Malik-Kotru G et al. (2006) Soft drinks and dental health: a review of the current literature. J Dent 34, 2-11.

3. World Health Organization (2003) Diet, Nutrition and the Prevention of Chronic Diseases. Joint WHO/FAO Expert 
Consultation. WHO Technical Report Series no. 916. Geneva: WHO.

4. Overby NC, Lillegaard IT, Johansson L et al. (2004) High intake of added sugar among Norwegian children and adolescents. Public Health Nutr 7, 285-293.

5. Rampersaud GC, Bailey LB \& Kauwell GP (2003) National survey beverage consumption data for children and adolescents indicate the need to encourage a shift toward more nutritive beverages. J Am Diet Assoc 103, 97-100.

6. Naska A, Bountziouka V \& Trichopoulou A (2010) Soft drinks: time trends and correlates in twenty-four European countries. A cross-national study using the DAFNE (Data Food Networking) databank. Public Health Nutr 13, 1346-1355.

7. Bere E, Glomnes ES, te Velde SJ et al. (2008) Determinants of adolescents' soft drink consumption. Public Health Nutr 11, 49-56.

8. Grimm GC, Harnack L \& Story M (2004) Factors associated with soft drink consumption in school-aged children. $J \mathrm{Am}$ Diet Assoc 104, 1244-1249.

9. Lien N, Lytle LA \& Klepp KI (2001) Stability in consumption of fruit, vegetables, and sugary foods in a cohort from age 14 to age 21. Prev Med 33, 217-226.

10. Nilsen SM, Krokstad S, Holmen TL et al. (2010) Adolescents' health-related dietary patterns by parental socio-economic position, the Nord-Trondelag Health Study (HUNT). Eur J Public Health 20, 299-305.

11. Vereecken CA, Inchley J, Subramanian SV et al. (2005) The relative influence of individual and contextual socioeconomic status on consumption of fruit and soft drinks among adolescents in Europe. Eur J Public Health 15, 224-232.

12. Kvaavik E, Andersen LF \& Klepp KI (2005) The stability of soft drinks intake from adolescence to adult age and the association between long-term consumption of soft drinks and lifestyle factors and body weight. Public Health Nutr $\mathbf{8}$, 149-157.

13. de Bruijn GJ, Kremers SP, de VH et al. (2007) Associations of social-environmental and individual-level factors with adolescent soft drink consumption: results from the SMILE study. Health Educ Res 22, 227-237.

14. Kassem NO, Lee JW, Modeste NN et al. (2003) Understanding soft drink consumption among female adolescents using the Theory of Planned Behavior. Health Educ Res $\mathbf{1 8}$, 278-291.

15. Kassem NO \& Lee JW (2004) Understanding soft drink consumption among male adolescents using the theory of planned behavior. J Behav Med 27, 273-296.

16. van der Horst K, Kremers S, Ferreira I et al. (2007) Perceived parenting style and practices and the consumption of sugar-sweetened beverages by adolescents. Health Educ Res 22, 295-304.

17. Denney-Wilson E, Crawford D, Dobbins T et al. (2009) Influences on consumption of soft drinks and fast foods in adolescents. Asia Pac J Clin Nutr 18, 447-452.

18. Feunekes GI, de Graaf C, Meyboom S et al. (1998) Food choice and fat intake of adolescents and adults: associations of intakes within social networks. Prev Med 27, 645-656.

19. Kremers SP, de Bruijn GJ, Visscher TL et al. (2006) Environmental influences on energy balance-related behaviors: a dual-process view. Int J Behav Nutr Phys Act 3, 9.

20. Andersen LF, Bere E, Kolbjornsen N et al. (2004) Validity and reproducibility of self-reported intake of fruit and vegetable among 6th graders. Eur J Clin Nutr 58, 771-777.

21. MacKinnon DP (2008) Introduction to Statistical Mediation Analysis. New York: Erlbaum.

22. Kenney DA, Kashy DA \& Bolger N (1998) The Handbook of Social Psychology, 4th ed. Boston, MA: McGraw-Hill.

23. Jaccard J, Turrisi R \& Wan CK (1990) Interaction Effects in Multiple Regression. London: SAGE Publications.

24. Haerens L, De BI, Maes L et al. (2007) The effects of a middle-school healthy eating intervention on adolescents' fat and fruit intake and soft drinks consumption. Public Health Nutr 10, 443-449.

25. Singh AS, Chin APM, Brug J et al. (2009) Dutch obesity intervention in teenagers: effectiveness of a school-based program on body composition and behavior. Arch Pediatr Adolesc Med 163, 309-317.

26. Bere E, van Lenthe F, Klepp KI et al. (2008) Why do parents' education level and income affect the amount of fruits and vegetables adolescents eat? Eur J Public Health 18, 611-615.

27. Bere E, Brug J \& Klepp KI (2008) Why do boys eat less fruit and vegetables than girls? Public Health Nutr 11, 321-325.

\section{Appendix}

\section{Overview of the questions and statements used for assessing the potential mediators of soft drinks consumption and the response alternatives/scores}

\begin{tabular}{|c|c|c|c|}
\hline Potential mediators & Questions/statements & $\begin{array}{l}\text { Response } \\
\text { alternatives }(n)\end{array}$ & Response alternatives (scores) \\
\hline Accessibility & $\begin{array}{l}\text { 1. How often are soft drinks to be found in your home? } \\
\text { 2. How often are you served soft drinks for dinner? } \\
\text { 3. How often does your mother/father serve you } \\
\text { soft drinks besides dinner? }\end{array}$ & 10 & $\begin{array}{l}\text { never }(0) \\
\text { less than once per month }(0 \cdot 1) \\
\text { less than once per week }[0 \cdot 5] \\
\text { once per week }(1) \\
\ldots \text { to } \\
\text { every day }(7)\end{array}$ \\
\hline Modelling & $\begin{array}{l}\text { 1. How often does your mother/father/siblings/best } \\
\text { friend drink soft drinks? }\end{array}$ & 10 & $\begin{array}{l}\text { never }(0) \\
\text { less than once per week }(0 \cdot 5) \\
\text { once per week }(1) \\
\ldots \text { to } \\
\text { every day }(7) \\
\text { several times per day }(10)\end{array}$ \\
\hline Attitudes & $\begin{array}{l}\text { 1. Soft drinks are well suited at meals } \\
\text { 2. Soft drinks are well suited as a thirst-quencher } \\
\text { 3. Soft drinks are good for your health }\end{array}$ & 5 & $\begin{array}{l}\text { I totally agree }(2) \\
\ldots \text { to } \\
\text { I totally disagree }(-2)\end{array}$ \\
\hline Preferences & 1. On a scale from 0 to 10 , how tasty do you find soft drinks? & 11 & 0 to 10 \\
\hline
\end{tabular}

